\title{
GEOMETRY AND INFORMATION FOR THE PRESERVATION OF A ROMAN MOSAIC THROUGH A HBIM APPROACH
}

\author{
D. Del Pozzo ${ }^{1}$, B.Scala ${ }^{2}$, A. Adami ${ }^{1 *}$ \\ ${ }^{1}$ Department of Architecture, Built Environment and Construction Engineering, Politecnico di Milano, Campus Mantova- \\ damiano.delpozzo@mail.polimi.it; andrea.adami@polimi.it \\ 2 Dicatam - Università degli studi di Brescia - barbara.scala@unibs.it
}

KEYWORDS: HBIM, mosaics, planned conservation, informative modeling

\begin{abstract}
:
The archaeological site is a mine of data and information that helps to deepen the knowledge of its origin, history, and structure. This virtuous approach becomes even more effective when these data, properly processed and structured, form the basis for a project of conservation and enhancement of the cultural asset.

The Roman mosaics dug in Castiglione delle Stiviere in 1995 represent an interesting case in which all the archaeological information, made available by the Superintendence, was used through an HBIM (Historical Building Information Modeling) approach for the conservation project. The Stratigraphic Units (US) of the findings have identified the strategy for the geometric and informative modeling of the BIM (Building Information Modeling) model and have also been exploited in the design phase for the project of the new roof structure and especially for the cost analysis. The structuring of the data by stratigraphic units was also used in the drafting of the preventive and planned conservation, necessary to enhance and prolong the state of good health of the property.

This work has been developed in the internship activity within a training course on HBIM, in collaboration with the Diocese of Mantua, owner of the property.
\end{abstract}

\section{INTRODUCTION}

\subsection{HBIM and archaeology}

For many years archaeology has approached digital technologies intending to refine the knowledge of heritage through accurate documentation operations, in-depth analysis, and reconstructive hypotheses. In this context, the technologies of geomatics (from laser scanning to photogrammetry) and computer graphics (including modeling) have contributed not only to knowledge but also to strengthen the interest in archaeology. Computer vision, with all the possibilities offered by virtual and augmented reality, has determined a great success of the communicative aspects. However, we must not forget that archaeological finds, whether single objects or architectural structures, well or badly preserved, also require conservation interventions. The preservation of archaeological structures has great affinities with architectural restoration; it starts from a thorough knowledge of the heritage and of the construction techniques and ends with the definition of restoration and planned preservation interventions to prolong the life of the asset (Della Torre, 2018). This affinity has led to the attempt to apply to the archaeological field the same systems that are trying to be applied to the historical and cultural heritage. These systems are HBIM (Historic Building Information Modeling) (Dore, Murphy, 2017) based on the concept of information modeling: the object is represented through geometric data and information; together they determine the knowledge necessary to make design choices. This approach brings with it some fundamental concepts such as interoperability and interest in the entire life cycle of the object.

The BIM (Building Information Modeling) approach to the architectural heritage cannot yet be defined as mature for an established professional practice. There are still many practical and conceptual difficulties that characterize the HBIM systems compared to the most mature field of BIM for new constructions.
A BIM Authoring software supports operations linked to standardization, an aspect very far from the conservative approach in which each element has its shape, frequently not regular, the result of craftsmanship or simply of time. The uniqueness of the object to be represented is very complicated with the tools made available by software.

However, since the objective of a conservation intervention is to maximize the conservation of the material, the objects represented shouldn't be replaced or modified, but only restored. In this case, the information model is very important and may require an integration of information greater than that provided by the software. This last eventuality is very frequent in archaeology: in fact, in addition to the information obtained from the excavations, it is possible to introduce data that are not related to a geometry now lost.

It is difficult to give a unique solution to all these difficulties, and in fact, the literature proposes very different approaches. For example, geometric modeling can be done in bim authoring software, or in $3 \mathrm{~d}$ modeling software, or very simplified. Also, the informative part can be managed through external relational databases built ad hoc. These possibilities, highlighted in the research, are contrasted, however, by the practical and concrete need for a single tool that clearly identifies a work process. We are looking for a solution that can, at least in part, respond to all needs through a commercial approach, ready to use, that does not require development phases, which will be the subject of research.

This research fits into this context, with two well-defined purposes. First, the definition of the best geometric BIM model which, according to the commercial software limits, starts from the needs of the project and the studies already carried out by archaeologists, thus focusing on stratigraphic aspects. Then, the goal is to use the BIM system for a conservation project that, although simplified, allows to protect a Roman floor mosaic through a covering structure.

\footnotetext{
* Corresponding author
} 


\subsection{A shared approach}

This project follows a common approach in the field of cultural heritage preservation.

The initial step is always a precise three-dimensional documentation work, carried out through geomatics tools - laser scanning and photogrammetry, often based on a topographic network. Data acquisition and processing, related to geomatic discipline, are well-known and widespread, because of many experiences in the field. The "ScanToBIM" process is, instead, very debated and current (Badenko et al., 2019, Rocha et al., 2020). The first, commonly recognized, difficulty is the lack of BIM Authoring software designed and developed for the existing cultural heritage, architectural and archaeological (Achille et al., 2015). The numerous commercial software, in fact, proposes tools for new constructions but are rigid in the application of these tools to the less standardized and regular forms of the existing heritage.

One solution approach is in the use of open-source BIM software (Diara, Rinaudo 2020) as an alternative method to BIM modeling, not only for structures but also for their stratigraphy (layers of materials). They implement a non-parametric modeling approach, in a BIM platform as FreeCAD, starting from a complete reality-based model to draw planar sections as the geometric generative curves for the NURBS (Non Uniform Rational B Splines) modeling. A similar approach is described by (Banfi, 2020) but using commercial software like Rhinoceros, to arrive at accurate modeling, not too heavy from the computation point of view.

Another field, instead, is the one related to the informative modeling, intended as all the historical, material, and degradation information that have to be linked to the model. This issue is at least as important as that of modeling because it has different rules from those of new construction, for which BIM systems were developed. Interesting work has been presented by (Scianna et. all., 2015), to describe archaeological sites through BIM software. The BIM models are made searchable - through the connection with a Relational Database Management System and shareable on the web. The case study was the Roman structures found in the Crypt of the Church of SS. Sergio e Bacco in Rome. In this context, another relevant research field is related to semantic segmentation, as the opportunity to subdivide the initial data, usually the point cloud, into smaller parts with common features: the aim is not to lose information in the passage from point cloud to geometric model.

It is intended, through this experience, to test the design on an architectural asset, in this case, a Roman mosaic, through an HBIM system. The case study and the specific objectives related to it are described in Session 2. Session 3 focuses on the method used starting from the survey (3.1), the modeling, both geometric and informative of today's situation (3.2), and the design (3.3). In Session 4, the discussion, the results of the research will be highlighted, explaining the positive and negative elements, not yet resolved.

\section{THE MOSAICS NEXT TO THE CONVENTO DI SANTA MARIA IN CASTIGLIONE DELLE STIVIERE}

The case study is to be found inside a fifteenth-century monastery in Castiglione delle Stiviere (Mantova) (Dal Prato, 1968). While demolishing a wing of the convent and the church annexed in the nineteenth century, the ruins of a Roman villa from the first and second century B.C. (before Christ), built in close proximity to a salutary spring discovered in the Etruscan era (Pancera, 2009), have been unearthed. It is not uncommon in this area to find ruins of Roman villas that had been probably owned by the Roman nobility, who saw Lake Garda as a spot where to spend their free time. The numerous examples of Roman villas discovered in the territory of the lower Garda Lake have been useful to the completion of the study case herein presented, especially to understand and compare the architectural elements found (Brogiolo, 1996)



Figure 1: Image of the area during the archaeological excavation of 1995 (source: Menotti, 2002).

The archaeological excavation process began in 1995 (Figure 1) Such operation brought to light parts of mosaics and wall structures that helped identify the different rooms which built the villa. It was far more extended than what the findings could tell; most of the structure had actually been destroyed during the realization of the convent, which preserves evident traces of how roman construction elements had been employed. The comparison with other villas in the area has allowed to speculate about the extension and the architectural features to be embedded in the HBIM model.

The Roman ruins are not very extended some spaces of a modest breadth and with various kinds of flooring. Two rooms, with preserved mosaic floors, were discovered, while in a third one, eleven meters wide, the remains of the praefurnium and the hypocaust were found. (Figure 2 and Figure 3). Other discoveries include the foundations of the medieval church and a tomb.

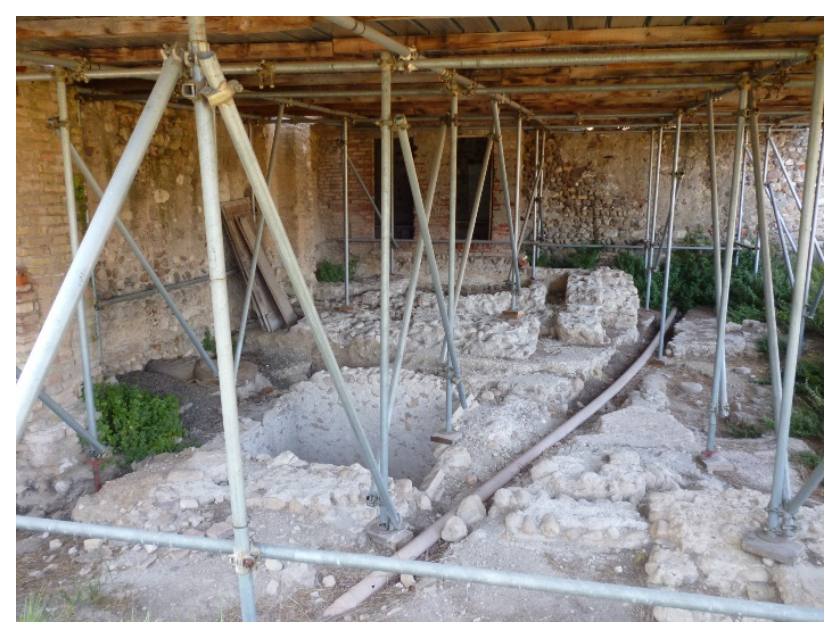

Figure 2: view of the archaeological area. The temporary roof cover lies directly on the archaeological structures, only protected by some protective layer.

The most important finding concerns a further space featuring a mosaic pavement flooring with black and white tiles positioned on three preparatory layers made of lime and opus signinum. 
Some other floors are made of pebbles submerged in a layer of lime mortar. The depicted themes are mainly geometrical: rhombuses and stars combined together to create tridimensional effects, curvilinear lines with acanthus volutes, and some pieces depicting the image of Bacchus and some animals.

The excavation has been currently protected with a temporary cover, waiting for the realization of a cover protection and a project of valorization.



Figure 3: photo of a geometric mosaic.

The proposition to develop an HBIM model for the area arises in agreement with the Cultural Heritage office and the technical office of Mantua diocese with the intent of systematizing the digitalization of the ecclesiastic heritage for better management. The archaeological site will soon be interested in future conservation intervention, therefore it is fundamental that all information collected from 1995 on is not dispersed, but rather be available during the project phase. Therefore, the model was organized to address the need to preserve and enhance the site

- systematizing the elaboration of stratigraphic analyses and identifying the existing different floor layers and superstructures by specifying the architectural features and the state of conservation;

- identifying possible interferences between the covering structure in progress to project and the remains so as to reduce them to the minimum and possibly taking into consideration variations in the project of said structure;

- developing a data collection system following planned conservation interventions considering in advance execution timing, costs, and obligations;

- organising the reading of the archaeological data by setting a valorization system that may allow to understand the structure of the villa as a whole and therefore facilitating the comprehension of the discovered ruins.

\section{METHOD AND WORKFLOW}

The workflow presented has the typical characteristics of a conservation project with the added value of an HBIM approach. As anticipated, in the archaeological field, as in other sectors, the research proceeds through different ways: on the one hand the search, up to the realization, of the most suitable software, on the other hand, the attempt to use commercial solutions, possibly integrated or interpreted according to the need, to verify if the whole process is effective and virtuous. The approach described in this paper follows this second direction and tries to use a commercial software package, Autodesk Revit software (used here in release 2018.3) which, although rigid, is more prevalent in the design culture than open-source systems

Starting from the 3D survey we developed a dataset of geometric elements and information (PDF, reports, images, maps), from which we created first a 3D information modeling of today situation and then a conservation project (both the covering structure and the conservation schedule), containing all the information needed by the stakeholder and the enterprises in charge of the works. Those files are linked as parameters of Autodesk Revit elements and are easily accessible to all the operators

In this way, information that was once closed in an archive now can be easily reached by stakeholders, researchers, workers, and even shared with the public visiting the site. We could imagine, for example, that through a simplified BIM viewer, visitors can interrogate the various constructional elements and read the story by way of those floors and mosaics, and have an idea of the antique roman villa.

Our idea was to use the existing archaeological survey to organize all the model element, link the information contained in the stratigraphic units to the model elements, and create a protocol of planning conservation which is going to notify the stakeholder when deadlines are approaching (Mason 2002).

With the standard Revit tools, this is not possible, but we developed a workaround solution that was still effective.

\subsection{The survey}

The survey of the mosaics-area has been made during the acquisition of the whole area which involves also the monastery and it applied different instruments and techniques.

As the archaeological excavations are concluded and no further inves tigations are planned at the moment, the part of the mosaics was surveyed in their current state of conservation, which did not allow to acquire mosaics in their best conditions. For this reason, the survey has provided for the acquisition by laser scanner and photogrammetry of the archaeological ruins and architectural structures for the scale of representation 1:50, while for the mosaics the orthophotos made by archaeologists to scale 1:20 have been used.

The survey has been done according to the commonly accepted principle of integrating data -from multiple sources and of a different type- in a single reference system based on topography. This allows to obtain a data model (Figure 4) which is more complete and suitable for further elaborations.

The first step of the survey has been the set-up of a topographic network, to georeferenced all data in a single local reference system. Measured by the total station Leica TS30, this network has been used to georeferenced the laser scanner survey of the villa with its surroundings (the archaeological findings) and the photogrammetric models obtained from terrestrial photos and UAV photos.

The laser scanner survey was made through the Leica HDS7000 phase shift instrument and we acquired, for the whole area, more than 100 scans ( 8 scans only in the archaeological area).

By using the Beecopter drone, an ultra-light UAV (Unmanned Aerial Vehicle), we surveyed the whole area with the villa, its fields, and the archaeological findings. More specifically, the images acquired by the drone were processed photogrammetrically to obtain a point cloud and orthophotos of the entire area (Adami et al., 2019).

After the acquisition stage, all data have been processed in specific software according to data typo (Agisoft Metashape for photos, Leica Cyclone for scans) and transferred into Autodesk Recap to be used directly in Autodesk Revit (Figure 4). This step 
has been fundamental: it allowed to model the geometry from a reality-based point cloud, which integrated the interior of the villa and its upperparts.

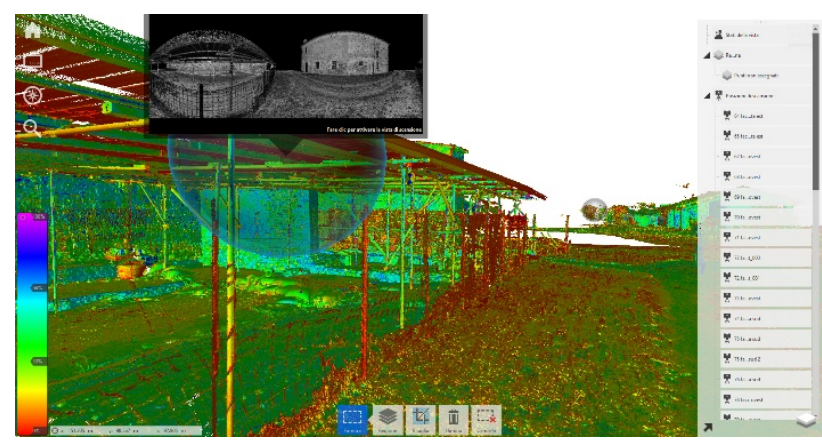

Figure 4: point-cloud of the archaeological area- The pointclouds are colored according to intensity. On the right, the structure of the $3 \mathrm{D}$ database with different scans. In the box, it's possible to see the scan as a panorama view.

In Revit, some limits in the visualization of the point-cloud make the process more complex: points dimension cannot be changed and the point-cloud color by elevation is not so adaptable. In this case, it is advisable to start the modeling process from Autodesk Autocad where the extraction of profiles is easier. As concerning the mosaic, for example, by setting the correct elevation color map we were able to distinguish, the boundaries of the mosaics, which are only $5 \mathrm{~mm}$ higher than the bedding layer (Figure 5). All profiles and boundaries, drawn in Autodesk Autocad, have been linked to Revit to guarantee continuous exchange and updating.

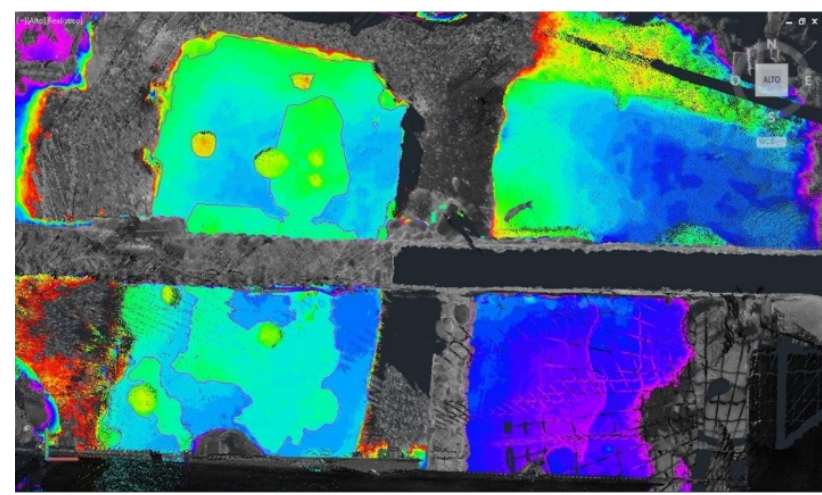

Figure 5: Different colors on the point-cloud according to elevation. From the colormap, it is possible to recognize the borders of the mosaics (the thickness of the mosaic is about $5 \mathrm{~mm}$ ).

The aim of the modeling stage was first the definition of today's state of the mosaic and the historical walls and remains, without dwelling on the temporary structures that shelter the archaeological area (Figure 6).

In this stage we dealt with different needs: archaeologists studied and worked on the villa, using a stratigraphic approach, so it was necessary to maintain it (and possibly to enhance this approach) We discussed with the engineer in charge of the structural project of the canopy about the support of the structure. He wanted to connect the canopy structure to the existing stone walls, those walls have a serious deformation that cannot be neglected. We had to think of a specific solution, and, before, to build an accurate model in the area of connection, modelling the out of plane deformation of the wall.

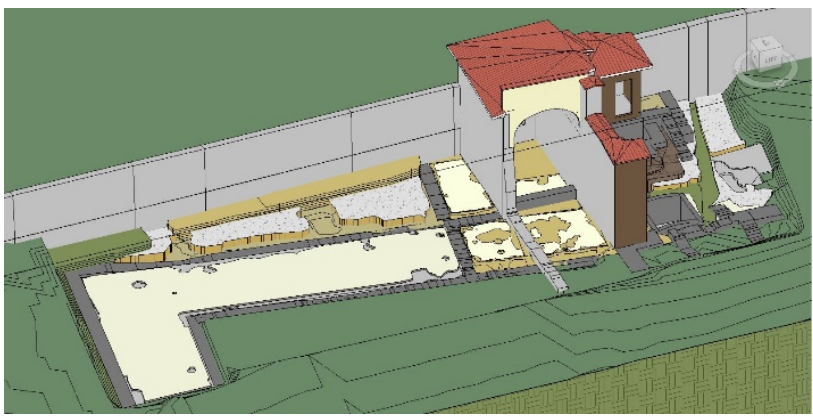

Figure 6: view of the whole model of the actual state of the archaeological area, without the temporary structure of coverage.

\subsubsection{Stratigraphy}

The role of information modeling is, at least, equal to that of geometric modeling, if not greater. Given the complexity of forms and materials, in fact, in many cases, it is opportune to entrust the specific description to the informative content and not to the geometric one, also to favor the real usability of the model and to avoid that it becomes too heavy and slow to manage.

As said, dealing with an archaeological site, we had to consider archaeologists' working methods. They had already dug, characterized, and identified all the elements found in the remains of the villa. Archaeologists use stratigraphy to study the layered materials (strata) that were deposited over time. The basic law (Harris 1989) of stratigraphy, the law of superposition, states that lower layers are older than upper layers unless the sequence has been overturned. Object types can be compared with those found at other sites, combined with stratification analysis and they can provide a basis for recognizing sequences in stratigraphic layers. For each layer (strata) archaeologists create a Stratigraphic Unit (SU) card and assign a unique ID to the element. In the card, we can find other useful information about its position, the material from which it is composed. the decays present, the conservation status, eventual findings, dating, and relationships between other SU.

Because all our elements were documented by archaeologists, we decided to maintain this principle and structure. We classified all our model elements with the Stratigraphic Unit parameter. Since the concept of layer is very close to the Revit System Family "Floor" we decided to create a floor for each SU.

Information, inside Revit, can be inserted in many ways and we tried to fulfill all the available parameters of the system families. Starting from point cloud data and processing then by elevation levels as described before, mosaics were created as geometric elements of the family "floor". So in "edit type", we created the exact layers: finishing, allurement mortar, screed, and bedding layer. For each layer, we used its specific material, whose composition was taken from the bibliography and the SU. For archaeologists, floor layers are different layers and should be kept different, but to be more coherent with the logic of the software - and as we did not need that specific information - we created all the floors as a unique element, even if it was possible to create each layer as a single floor. Only for some damaged floor, we kept the finishing layer as a single element, and all the underlying layers as a single element.

Creating a parameter of type "text" (or "number") for each field present on the SU report will result in an incredible long schedule, or the propriety box could result full of parameters and 
text information unable to be easily read. Having considered this, we have decided to store data in a single external folder for each Stratigraphic Unit. This folder, named $S U-n$ (number of the stratigraphic unit) contains:

- $S U-n$, the stratigraphic unit card, and the following sub-folders;

- Photos, with element organized by date of acquisition;

- Restoration, with all the drawings, reports, technical sheets, laboratory analysis, the restorer have produced;

- Maintenance, with the maintenance report, technical sheets, before-during-after pictures;

- Findings, with the photos, 3D models, links, of eventual findings.

This folder is linked in Revit by a URL parameter called Doc. Folder, by simply double-clicking on it, we can access to all the information, with only one parameter and when we need it. This approach allows having a lighter model. There is no necessity to characterize all the layers and all the materials inside modeling software; we can keep only the geometry element, with correct dimension because the thickness, the physical composition, the chemical composition of the layers, and the images are already described in the Maintenance Report, in the Restoration folder, and summarized in the SU card.

In the final 3D layout, we have indulged in graphic enhancement, which has been very useful. With the decals tool, we placed mosaics orthophoto on our floor element (Figure 7). The same pictures are contained in the folder, we have done it with the aim of historic disclosure.

To have a quick comprehension of the site's chronology, we created a filter for each historical phase, adding different color for each phase (Figure 12)

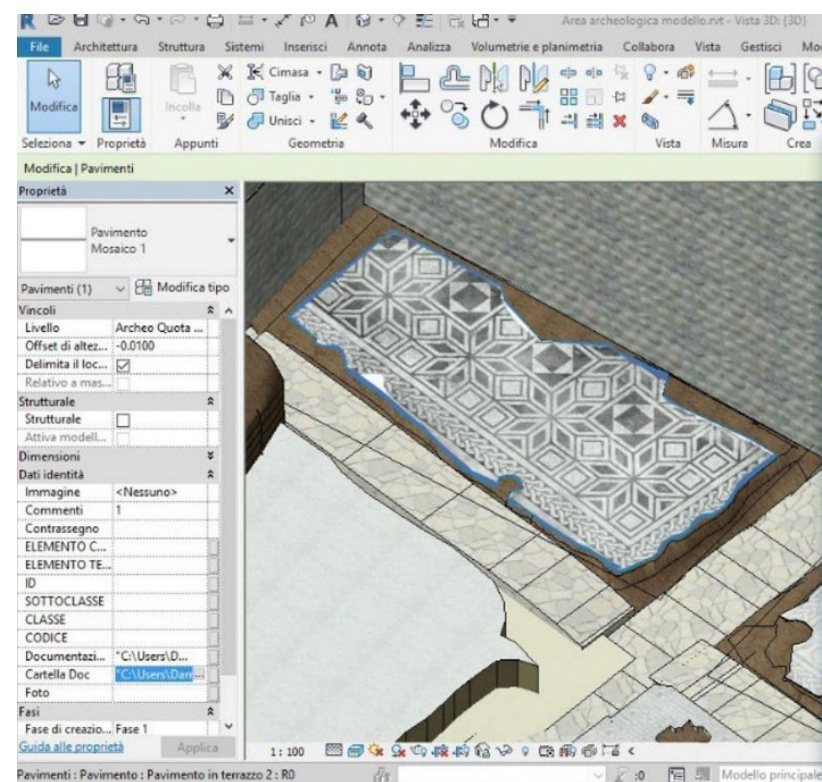

Figure 7: detail of the pavement with different layers (strata) and the mosaic orthophoto.

\subsection{The design}

3.2.1 The intervention

The preservation design commissioned by the Diocese of Mantua has been developed in two steps.

First, the design of a new structure which allows to protect the mosaics and, at the same time, to access the villa. Practically this has meant designing the canopy and the gangway in the least invasive way possible and responding to the need not only to preserve the mosaic but also to make it available for visits (Figure 9).

The new elements, specifically created for this case were the baluster of the gangways, the double C-shaped steel beams, which support the gangways, and their anchoring on the wall and the floor (Figure 8). The floor connections were simple concrete parallelepipeds with a steel wing in the middle, on which the double beams of the balustrade are bolted. We added parametric flanges at the ends of the beams for wall anchoring.



Figure 8: detail of the connection between the canopy and the existing structure.



Figure 9: rendered view of the suggested solution for the entrance with the walkway to pass through the mosaics and, at the same time, maintain visibility.

The use of the BIM approach allowed us also to face economic topics. archaeologists have already prepared the description of the work to restore the site, we focused on the economic estimation. Those works are usually calculated on surface and volume, quantities that Revit can ex tract without any problem. In our schedule, we used the following parameters: Surface, Type, 
Stratigraphic units, Execution year (number), Restoration intervention cost (currency), Total restoration (function, currency), (number), date of the inspection; (function, number),

\subsubsection{Planned preventive conservation}

Since the goal of restoration is made by the restoration intervention but also by continuous planner conservation, we paid attention to precise informative content connected with those aspects.

The starting point was the management system adopted in Pompei and described in (Osanna, Rinaldi, 2018) within the framework of the project "Towards a governance system for coordinating the updating and the implementation of the Management Plan of the Archaeological Areas of Pompei, Herculaneum, and Torre Annunziata

The mosaic and its subdivision into stratigraphic units were useful also in the planned conservation stage, as we used Revit as a filter tool.

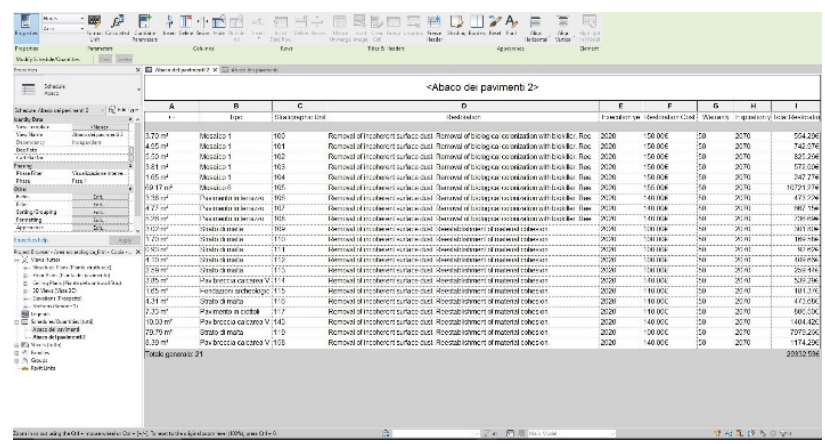

Figure 10: an estimate of material quantities and costs for the floor.

This approach has been useful in cost estimation as we use Working Breakdown Structure (WBS). Speaking of the conservation project, each SU could be a single WBS, because it has its materials, decays, which means different technological solutions for each SU. As an example, mosaics conservation needs different actions, products, tools from the conservation limestone rubble floor. This may result in a lot of WBS and related SU folders, but the stratigraphic method allows us, (after all the surveying and proper consideration were done) to equal single stratigraphic units which are fragments of the same elements.

We created a maintenance report, in PDF format and placed it in the Maintenance folder, inside the $S U-n$ main folder (Figure 11). Using this approach, the restoration enterprises have access to the information they need by a simple link to the folder, and they can download the Maintenance report, send it to the manpower on site by mail.

The conservation report is structured into two parts, the first contains general information about the element: the Stratigraphic Unit Number, the element type, his materials, the kind of work needed, some guidelines, best practices, and warnings, and a small plant where the element is highlighted. The second part contains information about the enterprise in charge of the works: a recall to the main chapter of the maintenance agreement in which the work performance is described in detail, the documents that must be associated, and space for eventual findings and notes.

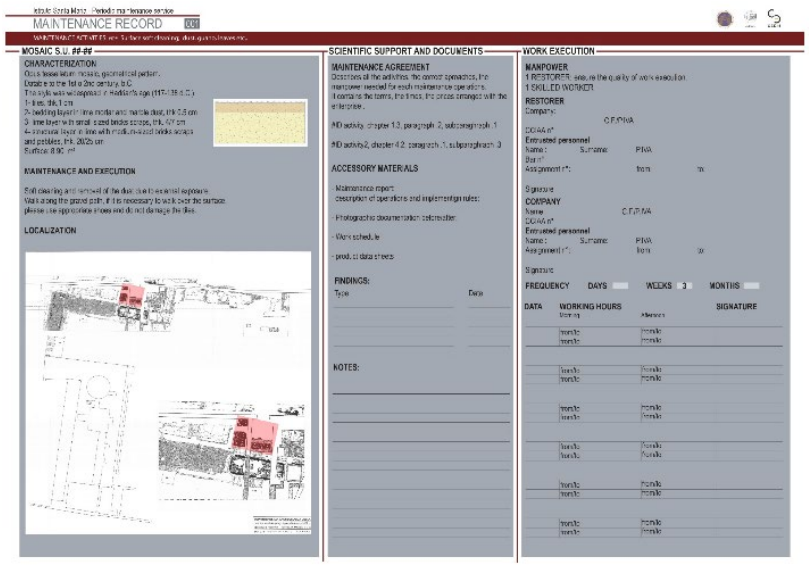

Figure 11: the maintenance report for the preventive conservation of the mosaic. It contains the description, localization, and recommendations for the conservation. In the last (right) part, the card to be filled by the employment of the conservation operation.

The report will be filled in (by tablet or pen) by the workers who will carry out the work, indicating also the identification of the subjects, the periodicity of maintenance, and "attendance record" with the timetable of the works.

\section{DISCUSSION}

In the final 3D layout, all elements of the mosaic and its context have been represented by geometry or by information. Apart from the archaeological structures, the case of the US is very explicative of the fact that the merge of geometric (size, shape, and position) and informative data (period, materials, etc.) can be a fundamental element not only for knowledge but also for the design, both of the restoration intervention and the planned conservation process. For example, to visualize the historical development of the area, according to the archaeologists assumptions (Figure 12).

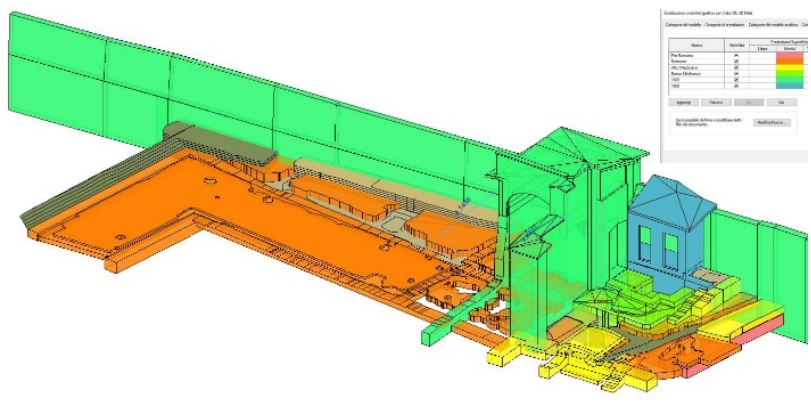

Figure 12: visualization of the archaeological area (mosaics and structures) according to the historical reconstruction made by archaeologists.

Some limitations of the software have forced us to choose solutions that are not always simple and straightforward. However, this has allowed us to structure a model that is easy to manage and use, in which diocesan offices can now enter all information related to planned storage, from inspection reports to new prescriptions. Moreover, it allowed the use of commercial software and, by the way, the possibility to reproduce the same method for other study cases.

The great advantage of this approach is that it allows for the management of both design and conservation as pects -materials, methods, and tools- and cost estimation, thus making the BIM tool operational. 
Approaching the theme of planned conservation, one of the most useful tools is the abacus, but there are some limits in Revit. One big flaw of this system is the horizontal layout, which turns out to be not practical for immediate consultation, and the length will increase with the number of parameters added.

Besides, the reorganization of the information provided by the Superintendency, regarding the archaeological excavations, has made it possible to systematize an archive and thus, virtually, to make it more accessible. However, there are still difficulties linked to the ownership of the data that, to date, make the process of complete data sharing impossible.

\section{CONCLUSIONS}

Approaching an archaeological site with BIM logic is possible and recommended: the modeling efforts and the attempts to force the software towards new applications are balanced by the possibility of having not only an organized and accessible archive but of being able to manage all the data according to conservation project.

This work shows the benefit of using the stratigraphic method approach not only for the archaeological study of the remains, but also to build the BIM model and organize the BIM process. We were able to bring inside a rudimental Common Data Environment all the information found in the superintendence archives, organize the model elements' ID with the SU number, create a link with a folder containing the SU card, and much other valuable information. We created the maintenance report, based on one or a group of SU.

\section{ACKNOWLEDGEMENTS}

This research was developed as an internship activity of the training course "HBIM Per $i$ beni culturali, strumenti per la progettazione, la modellazione e la gestione" (HBIM for cultural heritage, tools for design, modeling and management) organized by Politecnico di Milano.

A special thanks to the Diocese of Mantova (owner of the whole complex: the monastery and the roman mosaic remains) and the arch. Alessandro Campera (architect of the Diocese) for the cooperation and the sharing of data and objectives.

Other thanks to the Superintendence of Archaeology, Fine Arts and Landscape for the provinces of Cremona, Lodi and Mantua, in the person of Leonardo Lamanna, archaeologist, for the access at their archives and to archaeologist Lisa Cervigni, for giving us the original orthophotos of the mosaics.

\section{REFERENCES}

Achille, C., Lombardini, N., Tommasi, C., 2015 - BIM and cultural heritage: compatibility tests in an archaeological site, WIT Transactions on The Built Environment, 2015, Vol 149.

Adami, A., Fregonese, L., Gallo, M., Helder, J., Pepe, M., and Treccani, D.: Ultra Light Uav Systems for the metrical documentation of Cultural Heritage: applications for Architecture and Archaeology, Int. Arch. Photogramm. Remote Sens. Spatial Inf. Sci., XLII-2/W17, 15-21,

https://doi.org/10.5194/isprs-archives-XLII-2-W17-15-2019, 2019.

Badenko, V., Fedotov, A., Zotov, D., Lytkin, S., Volgin, D., Garg, R. D., and Liu, M.(2019). Scan-to-BIM methodology adapted for different applications, in Int. Arch. Photogramm. Remote Sens. Spatial Inf. Sci., XLII-5/W2, 1-7,

https://doi.org/10.5194/isprs-archives-XLII-5-W2-1-2019, 2019.

Banfi, F., 2020. HBIM, 3D drawing and virtual reality for archaeological sites and ancient ruins. Virtual Archaeology Review, [S.1.], v. 11, n. 23, p. 16-33, july 2020. ISSN 19899947.

Brogiolo 1996, La fine delle ville romane nelle campagne tra tarda antichità e alto medioevo, I Convegno Archeologico del Garda, Gardone Riviera (Brescia), SAP Società Archeologica S.r.l., Mantova. Pp. 107-110.

Diara, F., Rinaudo, F. (2020) Building archaeology documentation and analysis through open source HBIM solutions via NURBS modeling. In: International Archives of the Photogrammetry, Remote sensing and Spatial information sciences, vol. XLIII-B2-2020, pp. 1381-1388. ISSN 2194-9034.

Del Prato, 1968, Il convento di Santa Maria presso Castiglione delle Stiviere, in Chiese e conventi del contado mantovano, Vallecchi Editore, Firenze.

Della Torre, S., 2018. Restauro e progetto per l'archeologia. In Restaurando Pompei. Il grande progetto, edited by Osanna M., Picone R., L’Erma di Bretschneider, Roma, pp. 41-45.

Dore, C., Murphy, M. ,2017. Current state of the art Historic Building Information Modeling, in Int. Arch. Photogramm. Remote Sens. Spatial Inf. Sci., XLII-2/W5, 185-192, https://doi.org/10.5194/isprs-archives-XLII-2-W5-185-2017, 2017.

Harris, E. C, Principles of Archaeological Stratigraphy, Academic Pr, 1989.

Mason R. Assessing Values in Conservation Planning: Methodological Issues and Choices, in Assessing the Values of Cultural Heritage edited by De la Torre M. The Getty Conservation Institute, Los Angeles, pp 5-30,

Menotti, M.E., 2002, La villa romana di Santa Maria: archeologia a Castiglione delle Stiviere, Novastampa, Verona.

Pancera, A., 2009 Il Convento di Santa Maria. Osservazioni sul manufatto storico nel suo territorio, Litocolors R\&S, Guidizzolo, Mantova.

Rocha, G., Mateus, L., Fernández, J., Ferreira, V. 2020. "A Scan-to-BIM Methodology Applied to Heritage Buildings" Heritage 3, no. 1: 47-67. https://doi.org/10.3390/heritage3010004.

Scianna, A., Serlorenzi, M., Gristina S., Filippi, M., Paliaga, S.. 2015 Sperimentazione di tecniche BIM sull'archeologia romana: il caso delle strutture rinvenute all'interno della cripta della chiesa dei SS. Sergio e Bacco in Roma" In Archeologia e Calcolatori, Supplemento 7,2015,pp.199-212.

Osanna, M., Rinaldi, E., 2018. Planned conservation in Pompeii: complexity and methodological choices. In Journal of Cultural Heritage Management and Sustainable Development, Vol. 8 No. 2, pp. 111-129. https://doi.org/10.1108/JCHMSD05-2017-0025. 